\title{
Quitting Attempts in Bangladeshi Male Rural Smokers and Social Correlates
}

\author{
Flora $\mathrm{MS}^{1}$, Kabir I $^{2}$, Moni MA ${ }^{2}$ \\ ${ }^{1}$ Department of Biostatistics, National Institute of Preventive and Social Medicine, Dhaka, Bangladesh \\ ${ }^{2}$ Department of Epidemiology, National Institute of Preventive and Social Medicine, Dhaka, Bangladesh \\ e-mail: meerflora@yahoo.com
}

\begin{abstract}
Smokers lose, on average, about ten years of life, while smokers who quit before age of 35 years have mortality rates similar to those who never smoked. There is lack of support for smokers in their quitting attempt as well as empirical data to design support strategies. This cross sectional study was conducted in 2012 in rural Tangail, to identify the smoking quitting attempts and its correlates in Bangladeshi population. A total of 505 adult rural smokers were enlisted, and interviewed using a pretested questionnaire in Bangla. Pearson's chi-square tests and logistic regression analysis were done to find out the association before and after controlling for the effects of other variables. The recruited samples were between the ages of 18 and 80 years with a mean (SD) of 42.62 (13.10) years. About three-fourth of the participants $(72.5 \%)$ did not have any plan to quit smoking. Only $8.4 \%$ tried to quit smoking within last 12 months and $13.6 \%$ ever in their smoking life, and 5.2\% stopped smoking at least for a month. Intention to quit smoking associated with education $(p=0.025)$, age at starting smoking $(p<0.001)$, type of smokers $(p<0.001)$ and number of smoker friends $(p<0.001)$. Type of smokers $(p=0.001)$ and number of smoker friends $(p=0.002)$ showed influence on quitting attempt. Quit attempt was least common at homes $(p<0.001)$ and workplaces $(p<0.001)$ were there was no smoking restrictions. Only $5 \%$ tea stalls and $6 \%$ restaurants had partial smoking restrictions. About $60 \%$ respondent's family and $70 \%$ colleagues never tried to influence smokers to smoking. Those who were more frequently told more commonly tried to quit smoking $(p<0.001)$. The study revealed that smoking quitting intention and attempt both are at very low level in rural Bangladeshi males, and social attributes significantly correlated to intention and attempting smoking quit. Family and social support in quitting and restrictions at home and workplace might have role in motivating the smokers to quit smoking. To encourage smoking cessation, counseling service needs to be established and quitting aids should be made available at an affordable cost.
\end{abstract}

Key words: Smoking, Quit intention, Quit attempts, Social restrictions, Social support.

\section{Introduction}

The impact of tobacco on health has been extensively documented. Health consequences are of two-fold; first, the addictive nature of nicotine and second, disabling and fatal diseases caused by tobacco. ${ }^{1}$ Tobacco is the second major cause of death in the world and responsible for the deaths of one in ten adults worldwide. It is predicted to become the leading cause of death by 2020 s, causing more than one in every eight deaths. If current smoking patterns continue, it will cause some 10 million deaths each year by 2020 . Half of the people that smoke today will eventually be killed by tobacco. Tobacco is the fourth most common risk factor for disease worldwide. ${ }^{2}$ Tobacco consumption is the single most important preventable risk to health. Smokers lose, on average, about ten years of life. In a long-term prospective study of 35000 people, $81 \%$ of the non-smokers, but only $58 \%$ of the smokers, reached age $70 ; 59 \%$ of the non-smokers, but only $26 \%$ of the smokers, reached age $80 .^{3}$

Quitting smoking is beneficial to health at any age, and cigarette smokers who quit before age 35 years have mortality rates similar to those who never smoked. ${ }^{4,5}$ The benefits of smoking cessation in cardiovascular diseases are almost immediate. Within 24 hours of smoking cessation, significant improvements in blood pressure and heart 
rate are noted. Within one year of abstinence, the risk of cardiovascular events (e.g., myocardial infarction and stroke) is reduced by half (compared with continued smoking) and between 5 and 15 years post-smoking, the risk is "normalized" to that of never smokers. The benefits of tobacco treatment on the risk of lung cancer take much longer to achieve. The risk of lung cancer declines steadily following smoking cessation such that after about 10 years of abstinence, the risk of lung cancer is between $30 \%$ and $50 \%$ of that for continued smokers. However, even after decades of smoking cessation, the risk of lung cancer may never reach that of never smokers. The benefits of tobacco treatment to Chronic Obstructive Pulmonary Diseases (COPD) progression are measurable within the first year of abstinence. After several years of smoking cessation, the rate of decline in lung function becomes similar to that of never smokers. Smoking cessation is associated with a slower decline in lung function and reduced risk of hospitalization and total mortality. Patients with asthma also benefit from tobacco treatment as smoking cessation is associated with improved lung function, enhanced quality of life, and decreased reliance on rescue inhalers. Smoking cessation also reduces airway inflammation. ${ }^{6}$

Most smokers are motivated to quit smoking. In the United States (US) and United Kingdom (UK), nearly three out of four workers intend to quit smoking every year, yet fewer than $5 \%$ are able to quit successfully on their own. ${ }^{6}$ In the Netherlands $23 \%$ of smokers tried to stop smoking and $7 \%$ were reported to be successful. Smoking quitters had a higher socio-economic status and were particularly found among these Dutch respondents 44 years old or younger. ${ }^{7}$

Stopping smoking is a dynamic process quite often involving repeated attempts. Factors that lead an individual to stop smoking include beliefs about the benefit of quitting, medical advice, health scares and addiction. ${ }^{8}$ However, cessation rates in low- and middle-income countries are still very low compared with rates in the developed world. For example, while between $20 \%$ and $40 \%$ of smokers have quit in a number of developed countries, surveys found that the percentage of men reported to have stopped was only $2 \%$ in China, $5 \%$ in India, and $10 \%$ in Vietnam. In addition, research has found that without help in the form of cessation treatment, up to $98 \%$ of smokers who try to quit will start again within a year. ${ }^{9}$ Larabie reported that the majority of quit attempts $(51 \%)$ were unplanned. ${ }^{8}$

Nearly one third of the population in Bangladesh use some form of tobacco; the overall prevalence of smoking and chewing tobacco are $20.5 \%$ and $20.6 \%$ respectively. Current smoking is significantly higher in males $(42.2 \%)$ than in females $(2.3 \%)$ while chewing tobacco is more common in females $(21.6 \%)$ than males $(19.4 \%)$. Only $8 \%$ are ex-smokers which means has quitted smoking successfully. ${ }^{10}$ Smoking prevalence among Bangladeshi men $(49 \%)$ is significantly higher than among Pakistani $(28 \%)$, Indian $(19 \%)$, or white men in the UK (29\%). There is little published research on smoking cessation in Pakistani and Bangladeshi people in the $\mathrm{UK},{ }^{11}$ while this was seldom investigated in Bangladeshi population. Overall, $21.8 \%$ of the smokers were found to make quit attempts (that is, making at least one quit attempt in that lasted for at least 24 hours) in a study. ${ }^{12}$ Intention of quitting data could not be found so far literature reviewed. It has also been reported that the social encouragement is associated with intention to undergo smoking cessation treatment and to abstain. ${ }^{13}$ The study attempted to find out the quit attempts in Bangladeshi smokers and its link with social attributes.

\section{Materials and Methods}

This was a cross-sectional study done on adult male smokers in rural Bangladesh. Smoking is more prevalent in the country among the males. A very limited number of females smoke and due to cultural prohibition they also donlt feel comfortable to discuss with this issue. This study therefore targeted only the male smokers. The previous data suggested that $23 \%$ of the smokers attempted to stop smoking. ${ }^{7}$ Considering these data at $95 \%$ confidence limit and with $3 \%$ absolute precision the estimated sample size was 386. Considering $40 \%$ smoking rate to get 386 smokers 965 households were targeted. Finally, 986 households from purposively selected villages in Ghatail sub-district of Tangail district were included in the study. At first, a census was done in the selected villages to screen in the smokers. A total of 505 adult current smokers were identified and all were recruited in the study. The survey instrument was prepared consulting the available instruments in different domains related to objectives of the study. The questions were translated into Bangla and adapted according to our culture before use. 
Social attributes included variables related to social including home and family support towards quitting, restrictions towards smoking and social environment. The instrument also included questions on socio-demographic characteristics. Before using, the tool was pre-tested in Dhamrai subdistrict of Dhaka district, an area having similar geographic and socio-economic characteristics. Data were collected through interview. Four male data collectors were recruited and extensively trained on the data collection and consent process. Those who willingly participated in the research only were recruited as study participants. Consent was obtained after explaining study objectives and procedure. For quality control of data a research officer was appointed to supervise the data collection intensively. In addition, the investigators themselves also visited the data collection site. Five percent of the sample were re-interviewed and examined. All the collected data were cleaned, edited and analyzed using software package SPSS 16.0. Univariate tests were done to find out the statistical association. To control for the effect of the confounding variables logistics regression models were constructed. Ethical approval was obtained from ethical committee of the National Institute of Preventive and Social Medicine, Dhaka.

\section{Results}

The recruited samples were male smokers between the ages of 18 and 80 years; and the mean (SD) and median age were 42.62 (13.10) and 42.00 years, respectively. All were Muslims.

About three-fourth of the participants $(72.5 \%)$ did not have any plan to quit smoking. Only two expressed their intention to quit smoking within a month, 5.6\% within next six months, and another $21.4 \%$ sometime in future. About a fourth of the respondents $(23.1 \%)$ who had intention to quit smoking were not at all confident about their success in quitting. Majority (64.3\%) were a bit sure, $10.5 \%$ somewhat, $0.7 \%$ very and $1.4 \%$ completely sure about their success. Only $8.4 \%$ participants tried to quit smoking during the last 12 months of data collection and $13.6 \%$ ever in their smoking life. Out of all smokers only $7.2 \%$ could ever stop smoking for one day. During the last one year of data collection $7.7 \%$ stopped smoking at least for one day and $6.6 \%$ and $5.2 \%$ at least for a week and a month respectively.
Table I: Background characteristics and intention and attempt to quit

\begin{tabular}{|c|c|c|c|}
\hline $\begin{array}{c}\text { Characteris- } \\
\text { tics }\end{array}$ & $\mathbf{N}(\mathbf{5 0 5})$ & $\begin{array}{c}\text { Intention to } \\
\text { quit (137) }\end{array}$ & $\begin{array}{c}\text { Attempt to quit } \\
\text { (42) }\end{array}$ \\
\hline \multicolumn{4}{|l|}{ Age in vears } \\
\hline$<30$ & $86(17.0)$ & $28(32.9)$ & $6(7.1)$ \\
\hline $30-39$ & $110(21.8)$ & $22(20.0)$ & $7(6.4)$ \\
\hline $40-49$ & $136(26.9)$ & $39(29.1)$ & $11(8.2)$ \\
\hline $50-59$ & $105(20.8)$ & $26(25.2)$ & $13(12.6)$ \\
\hline $60-69$ & $49(9.7)$ & $17(35.4)$ & $3(6.3)$ \\
\hline $70+$ & $19(3.8)$ & $5(26.3)$ & $2(10.5)$ \\
\hline \multicolumn{4}{|c|}{ Educational status } \\
\hline Illiterate & $140(27.7)$ & $49(35.5)^{*}$ & $15(10.9)$ \\
\hline Can sign only & $177(35.0)$ & $34(19.4)$ & $12(6.9)$ \\
\hline Up to primary & $56(11.1)$ & $18(33.3)$ & $3(5.6)$ \\
\hline Secondary & $68(13.5)$ & $18(26.5)$ & $6(8.8)$ \\
\hline $\begin{array}{l}\text { SSC and } \\
\text { above }\end{array}$ & $64(12.7)$ & $18(28.1)$ & $6(9.4)$ \\
\hline \multicolumn{4}{|l|}{ Occupations } \\
\hline Non-paid & $28(5.5)$ & $7(25.0)$ & $3(10.7)$ \\
\hline Farmer & $185(36.6)$ & $53(28.8)$ & $15(8.2)$ \\
\hline Day labourer & $56(11.1)$ & $7(12.7)$ & $5(9.1)$ \\
\hline $\begin{array}{l}\text { Rickshaw- } \\
\text { puller }\end{array}$ & $38(7.5)$ & $10(26.3)$ & $2(5.3)$ \\
\hline Service & $40(7.9)$ & $8(20.0)$ & $4(10.0)$ \\
\hline $\begin{array}{l}\text { Skilled la- } \\
\text { bourer }\end{array}$ & 75 (14.9) & $26(35.1)$ & $8(10.8)$ \\
\hline \multirow{2}{*}{\multicolumn{4}{|c|}{ Marital status }} \\
\hline & & & \\
\hline Single & $27(5.3)$ & $6(22.2)$ & $2(7.4)$ \\
\hline Married & $478(94.7)$ & $131(27.8)$ & $40(8.5)$ \\
\hline \multicolumn{4}{|c|}{ Age at starting smoking } \\
\hline$<15$ & $28(5.6)$ & $13(46.4)^{*}$ & $3(10.7)$ \\
\hline $15-19$ & $145(29.1)$ & $64(44.1)$ & $17(11.7)$ \\
\hline $20-24$ & $226(45.3)$ & $49(21.7)$ & $17(7.5)$ \\
\hline $25-29$ & $71(14.2)$ & $5(7.0)$ & $4(5.6)$ \\
\hline & $29(5.8)$ & $6(20.7)$ & $1(3.4)$ \\
\hline \multicolumn{4}{|c|}{ Type of smokers } \\
\hline Light & $33(6.6)$ & $23(69.7) *$ & $9(27.3)^{*}$ \\
\hline Moderate & $445(89.2)$ & $109(24.5)$ & $30(6.7)$ \\
\hline Heavy & $21(4.2)$ & $5(23.8)$ & $3(14.3)$ \\
\hline \multicolumn{4}{|c|}{ Number of smoker friend } \\
\hline Few to some & $36(7.2)$ & $28(77.8) *$ & $6(16.7)^{*}$ \\
\hline Most & $352(70.5)$ & $105(29.8)$ & $34(9.7)$ \\
\hline All & $111(22.3)$ & $4(3.6)$ & $2(1.8)$ \\
\hline
\end{tabular}

More than one-fourth of the study participants were in 40-49 years age group and about $14 \%$ were elderly. Majority was married (94.7\%) and never went to school (62.7\%). One-third was farmers $(36.6 \%)$ and another one-third included skilled (14.9\%) and unskilled labourer (11\% daily labourer and $7.5 \%$ rickshaw-puller). More than five percent were in non-paid occupations including students, unemployed, retired and household works (table I).

Respondents in 60-69 years age group and $<30$ years more commonly showed intention to quit smoking than other age groups although the findings were not significant $(p>0.05)$. Education 
showed significant association with intention to quit smoking although no particular pattern was seen $(p=0.025)$. Intention was least common in the respondents who could sign only, whereas highest in illiterates and primary level educated. Occupation and marital status did not show any association with intention to quit.

Respondents of 50-59 years (12.6\%) and 70+ years $(10.6 \%)$ more commonly attempted to quit. One-tenth of illiterate and SSC+ respondents attempted to quit. Attempt to quit was more common in skilled labourer $(10.8 \%)$, non-paid $(10.7 \%)$ and service holders (10\%). Married smokers $(8.5 \%)$ tried more commonly to quit smoking than their single counterparts $(7.4 \%)$. But no significant difference was noted in proportion of quit attempts among different ages, education, occupations and marital status $(p>0.05)$.

More than one-third started to smoke at their adolescence and $45.1 \%$ started at an age between 20 and 24 years. Majority were moderate smokers. Intention to quit smoking associated with age at starting smoking $(p<0.001)$ and type of smokers $(p<0.001)$. After removing the effect of educational status influence of type of smokers on intention to quit persisted. Moderate (OR 0.14; $95 \%$ CI 0.06 to 0.30 ) and heavy smokers (OR 0.13 ; 95\% CI 0.04 to 0.46 ) were seven and seven and half times less likely to have intention to quit smoking.

Age at starting of smoking did not show any influence on quitting attempt but type of smokers did $(p=0.001)$. Light smokers more commonly attempted to quit smoking. Moderate smokers were five times more likely not to attempt quitting smoking (OR 5.23; 95\% CI 2.23 to 12.27) than the light and heavy smokers. Respondents were asked about the smoking status of their friends whom they used to meet regularly and none were nonsmokers. Majority of the respondents had most of the friends smoking (70.5\%) and $22.3 \%$ had 'all friends smoking'. Intention and quit attempt both depended on the number of smoker friends; more the smoker friends less was the intention $(p<0.001)$ and attempt to quit $(p=0.002)$. After controlling for the effect of education, age at starting smoking and type of smoker the association between number of smoker friends and intention to quit remained significant. Smokers having all (OR $0.01 ; 95 \%$ CI 0.003 to 0.04 ) and most (OR 0.18 ; $95 \%$ CI 0.07 to 0.42 ) smoker close friends were 90 and 6 times, respectively, less likely to have intention to quit than having a few smoker friends. After removing the effect of type of smokers the association of number of smoker friends with attempt to quit persisted. Smokers having all friends smokers (OR 8.85; 95\% CI 1.66 to 47.16) were about nine times more likely not to attempt quitting than their counterparts.

To find out the social correlates of quit attempts level of social restrictions were assessed (table II).

Data related to smoking restrictions at different places including home, workplaces, mosque and other places of social gatherings were collected and their influence on quit attempt was ascertained. Only four percent households had strict restrictions about smoking and quit attempt was highest among them. Quit attempt was least common where there were no smoking restrictions at home $(p<0.001)$ and smokers residing at those home were six times less likely to attempt to quit smoking (OR 0.16; 95\% CI 0.05 to 0.53 ) than others after controlling for the effect of type of smokers and smokers friends. Smoking restrictions at workplaces also showed influence on quit attempts $(p<0.001)$.

One-third of the respondents working at places with restricted smoking zone attempted to quit smoking. Smokers working at non-restricted workplaces were five and half times less likely to attempt quitting than smokers working in fully or partially restricted workplaces (OR $0.18 ; 95 \%$ CI 0.05 to 0.61 ). Except few all respondents reported to have smoking restrictions at mosques. Restriction about smoking in tea stall and restaurants of that locality were also explored and found that only one tea stall and one restaurant had complete and 5\% tea stalls and $6 \%$ restaurants had partial 
restrictions and more than one third respondents who visited those places attempted to quit. The quit attempt was less common where either there was no restriction or no rule about smoking.

Table II: Restrictions for smoking at different places and quit attempt

\begin{tabular}{|c|c|c|c|c|}
\hline \multirow{2}{*}{$\begin{array}{c}\text { Restrictions } \\
\text { to smoke }\end{array}$} & \multicolumn{2}{|c|}{ Attempted last year } & \multirow{2}{*}{$\begin{array}{l}\text { Total } \\
\text { n }(\%)\end{array}$} & \multirow{2}{*}{$\begin{array}{c}p- \\
\text { value* }\end{array}$} \\
\hline & $\begin{array}{c}\text { No } \\
\text { n }(\%)\end{array}$ & $\begin{array}{c}\text { yes } \\
\text { n }(\%)\end{array}$ & & \\
\hline \multicolumn{5}{|l|}{ Home } \\
\hline Not at all al- & $17(77.3)$ & $5(22.7)$ & 22 & \multirow{2}{*}{$<0.001$} \\
\hline Allowed in & 132 & 26 & 158 & \\
\hline Allowed eve- & 308 & $11(3.4)$ & 319 & \\
\hline \multicolumn{5}{|l|}{ Workplace } \\
\hline Not allowed & $23(82.1)$ & $5(17.9)$ & 28 & \multirow{4}{*}{$<0.001$} \\
\hline Allowed in & $38(65.5)$ & 20 & 58 & \\
\hline Allowed eve- & $65(90.3)$ & $7(9.7)$ & 72 & \\
\hline No rule & 331 & $10(2.9)$ & 341 & \\
\hline \multicolumn{5}{|l|}{ Mosque } \\
\hline Not allowed & 449 & $42(8.6)$ & 491 & \multirow{3}{*}{ Ns } \\
\hline Allowed eve- & $4(100.0)$ & $0(0)$ & $4(0.8)$ & \\
\hline No rule & $4(100.0)$ & $0(0)$ & $4(0.8)$ & \\
\hline \multicolumn{5}{|l|}{ Tea stall } \\
\hline Not allowed & $0(0)$ & 1 & $1(0.2)$ & \multirow[t]{3}{*}{0.006} \\
\hline Allowed in & $20(80.0)$ & $5(20.0)$ & 25 & \\
\hline No rule & 437 & $36(7.6)$ & 473 & \\
\hline \multicolumn{5}{|l|}{ Restaurants } \\
\hline Not allowed & $1(100.0)$ & $0(0)$ & $1(0.2)$ & \multirow{4}{*}{$<0.001$} \\
\hline Allowed in & $19(63.3)$ & 11 & 30 & \\
\hline Allowed eve- & 314 & $17(5.1)$ & 331 & \\
\hline Own rule & 121 & 14 & 135 & \\
\hline
\end{tabular}

Support by the family, colleagues at work places and in mosques and their influence on quit attempts were assessed. To explore family support a few approaches were mentioned and responses were recorded as 'never' 'sometimes' 'often' and 'always' done by the spouse and family. The support provided by the spouse to married respondents during their quitting attempts were also explored (table III). About $40 \%$ always and an additional $30 \%$ often expressed their happiness, and one-fourth always, one-fourth sometimes and more than one-third often showed confidence. But most of them (86\%) never encouraged continuing the attempt. Majority of respondents helped to calm down sometimes (43\%), often (43\%) and to find alternatives $(46 \%$ and $21 \%$, sometimes and often, respectively); praised for not smoking (39\% and $36 \%$, sometimes and often, respectively).
Table III: Support by wife while attempted to quit

\begin{tabular}{|c|c|c|c|c|}
\hline $\begin{array}{c}\text { Support by } \\
\text { wife }\end{array}$ & Never & $\begin{array}{c}\text { Some- } \\
\text { times }\end{array}$ & Often & Always \\
\hline $\begin{array}{l}\text { Praised for not } \\
\text { smoking }\end{array}$ & $3(8.3)$ & $\begin{array}{l}14 \\
(38.9)\end{array}$ & $\begin{array}{l}13 \\
(36.1)\end{array}$ & $6(16.7)$ \\
\hline $\begin{array}{l}\text { Helped to find } \\
\text { alternatives }\end{array}$ & $\begin{array}{l}4 \\
(16.7)\end{array}$ & $\begin{array}{l}11 \\
(45.8)\end{array}$ & $\begin{array}{l}5 \\
(20.8)\end{array}$ & $4(16.7)$ \\
\hline $\begin{array}{l}\text { Helped to calm } \\
\text { down }\end{array}$ & $3(8.6)$ & $\begin{array}{l}15 \\
(42.9)\end{array}$ & $\begin{array}{l}15 \\
(42.9)\end{array}$ & $2(5.7)$ \\
\hline $\begin{array}{l}\text { Encouraged to } \\
\text { continue the at- } \\
\text { tempt }\end{array}$ & $\begin{array}{l}30 \\
(85.7)\end{array}$ & $2(5.7)$ & $1(2.9)$ & $2(5.7)$ \\
\hline $\begin{array}{l}\text { Showed confi- } \\
\text { dence in quit- } \\
\text { ting capability }\end{array}$ & $3(8.8)$ & $9(26.5)$ & $\begin{array}{l}13 \\
(38.2)\end{array}$ & $9(26.5)$ \\
\hline $\begin{array}{l}\text { Expressed hap- } \\
\text { piness in quit- } \\
\text { ting attempt }\end{array}$ & $\begin{array}{l}4 \\
(12.1)\end{array}$ & $6(18.2)$ & $\begin{array}{l}10 \\
(30.3)\end{array}$ & $\begin{array}{l}13 \\
(39.4)\end{array}$ \\
\hline
\end{tabular}

Table IV: Role of family and quit attempt

\begin{tabular}{|c|c|c|c|}
\hline Role of family & $\begin{array}{c}\mathbf{N} \\
\mathbf{n}(\%)\end{array}$ & $\begin{array}{c}\text { Attempted } \\
\text { n (\%) }\end{array}$ & $p$-value* \\
\hline \multicolumn{4}{|c|}{ Family asked to quit in last six months } \\
\hline Never & $181(36.3)$ & $2(1.1)$ & \multirow{4}{*}{$<0.001$} \\
\hline Sometimes & $234(47.0)$ & $14(6.0)$ & \\
\hline Often & $48(9.6)$ & $11(22.9)$ & \\
\hline Always & $35(7.0)$ & 15 (42.9) & \\
\hline \multicolumn{4}{|c|}{ Family criticized about lack of will power } \\
\hline Never & $298(59.8)$ & $7(2.3)$ & \multirow{3}{*}{$<0.001$} \\
\hline $\begin{array}{l}\text { Sometimes } \\
\text { Often }\end{array}$ & $\begin{array}{l}82(16.5) \\
96(19.3)\end{array}$ & $\begin{array}{l}14(17.1) \\
13(13.5)\end{array}$ & \\
\hline Always & $22(4.4)$ & $8(36.4)$ & \\
\hline \multicolumn{4}{|c|}{ Family did not like bad smell in home } \\
\hline Never & $296(59.4)$ & $8(2.7)$ & \multirow{4}{*}{$<0.001$} \\
\hline Sometimes & $68(13.7)$ & $9(13.2)$ & \\
\hline Often & $38(7.6)$ & $12(31.6)$ & \\
\hline Always & $96(19.3)$ & $12(12.5)$ & \\
\hline \multicolumn{4}{|c|}{ Did not allow to smoke in home } \\
\hline Never & $310(62.5)$ & $10(3.2)$ & \multirow{4}{*}{$<0.001$} \\
\hline Sometimes & $84(16.9)$ & $10(11.9)$ & \\
\hline Often & $56(11.3)$ & $8(14.3)$ & \\
\hline Always & $46(9.3)$ & $14(30.4)$ & \\
\hline \multicolumn{4}{|c|}{ Considered smoking as a bad habit } \\
\hline Never & $325(65.3)$ & $9(2.8)$ & \multirow{4}{*}{$<0.001$} \\
\hline Sometimes & $73(14.7)$ & $13(17.8)$ & \\
\hline Often & $56(11.2)$ & $9(16.1)$ & \\
\hline Always & $44(8.8)$ & $10(22.7)$ & \\
\hline \multicolumn{4}{|c|}{ Had problem with smoking } \\
\hline Never & $326(67.2)$ & $12(3.7)$ & \multirow{4}{*}{$<0.001$} \\
\hline Sometimes & $47(9.7)$ & $8(17.0)$ & \\
\hline Often & $34(7.0)$ & $3(8.8)$ & \\
\hline Always & $78(16.1)$ & $7(9.0)$ & \\
\hline
\end{tabular}


Table V: Support at the mosque and workplace and quit attempt

\begin{tabular}{|c|c|c|c|c|}
\hline \multirow{2}{*}{$\begin{array}{c}\text { Role of } \\
\text { colleagues }\end{array}$} & \multicolumn{2}{|c|}{ Mosque } & \multicolumn{2}{|c|}{ Workplace } \\
\hline & $\begin{array}{l}\mathbf{N} \\
\mathbf{n}\end{array}$ & $\begin{array}{l}\text { Attempted } \\
\mathbf{n}(\%)\end{array}$ & $\begin{array}{l}\mathbf{N} \\
\mathbf{n}\end{array}$ & $\begin{array}{c}\text { Attempted } \\
\text { n }(\%)\end{array}$ \\
\hline \multicolumn{5}{|c|}{ Asked to quit in last 6 months* } \\
\hline Never & 288 & $11(3.8)$ & 354 & $9(2.5)$ \\
\hline Sometimes & 148 & $9(6.1)$ & 62 & $16(25.8)$ \\
\hline Often & 38 & $7(18.4)$ & 59 & $6(10.2)$ \\
\hline Always & 24 & $14(58.3)$ & 21 & $11(52.4)$ \\
\hline \multicolumn{5}{|c|}{ Criticized Smoking* } \\
\hline Never & 361 & $12(3.3)$ & 358 & $8(2.2)$ \\
\hline Sometimes & 30 & $3(10.0)$ & 28 & $11(39.3)$ \\
\hline Often & 12 & $4(33.3)$ & 9 & $0(0)$ \\
\hline Always & 95 & $22(23.2)$ & 101 & $22(21.8)$ \\
\hline \multicolumn{5}{|c|}{ Considered smoking as a bad habit* } \\
\hline Never & 343 & $11(3.2)$ & 355 & $9(2.5)$ \\
\hline Sometimes & 53 & $8(15.1)$ & 56 & $7(12.5)$ \\
\hline Often & 81 & $14(17.3)$ & 68 & 19 (27.9) \\
\hline Always & 21 & $8(38.1)$ & 17 & $7(41.2)$ \\
\hline
\end{tabular}

Percentage shown in parenthesis. * Findings were statistically significant by chi-square test at $p<0.001$.

About 60\% respondents' family never tried to influence smokers to stop smoking saying 'respondent lack willpower', smoking causes bad smell in house', 'smoking in not allowed at home', 'smoking is bad habit' and 'have problem with smoking and one-third of the respondent' family never asked them in last six months to quit (table IV). Less than $10 \%$ always encouraged saying the above statements except $19 \%$ and $16 \%$ respondents always complaint of bad smell at home and having problem due to smoking, respectively. Those who were more frequently told were more commonly tried to quit smoking ( $\mathrm{p}<0.001$ ).

The smokers were either never or very infrequently told to quit smoking $(57.8 \%$ and $29.7 \%$, respectively), criticized about smoking $(72.5 \%$ and $6 \%$, respectively) and reminded it as a bad habit $(68.9 \%$ and $10.6 \%$, respectively) in the mosques. Those who were always or frequently asked to do so, tried to quit smoking more commonly $(p<0.001)$.

More than $70 \%$ colleagues in the workplace were never told anything about quitting. Only four percent were always asked to quit smoking and more than half of them tried. Twenty percent were always criticized for their smoking but only $21.8 \%$ of them attempted. About $40 \%$ of those who were sometimes criticized attempted to quit. Only $3.4 \%$ were always and $13.7 \%$ often told 'smoking is a bad habit and $41.2 \%$ and $27.9 \%$, respectively, tried to quit smoking. All these findings were statistically significant $(p<0.001)$, and are presented in table $\mathrm{V}$.

\section{Discussion}

Smoking is a long-standing problem for Bangladeshi males especially for the poor and rural residents. If nothing changes, the impact of tobacco on health and human productivity in Bangladesh like other developing world is set to become much worse, rather than remain constant or improve. The antismoking campaign in Bangladesh mainly focuses on prevention of smoking. Quitting of smoking also shows significant health benefit in many studies. Current and past smokers had significantly higher risk of myocardial infarction than never smokers, while current smokers show more risk than past smokers. ${ }^{13}$ In some conditions with the withdrawal of smoking the body mechanisms return to its almost pre-smoking period. For development of a programme package to assist the smokers who intended or attempted to quit smoking epidemiological data are required. Very limited data for Bangladeshi population are available. As the prevalence of smoking is higher in rural and male population, the study was conducted in rural male smokers.

Patients who try to quit smoking on their own rarely achieve complete abstinence over time. Initially, $25-50 \%$ of patients succeed; however, by 3 months, the success rate drops off to only $10-20 \%$, and by 6 months, $95-97 \%$ of those who tried are back smoking. ${ }^{6}$ Only $13.6 \%$ ever and $8.4 \%$ during the last 12 months of the current study tried to quit smoking. During the last one year of data collection $7.7 \%$ stopped smoking for one day, $6.6 \%$ for a week and $5.2 \%$ for a month only.

A panel study reported that, older age, less education, and lower income are associated with absence of intention to quit. ${ }^{14}$ Studies have found that probability of making quit attempts vary by demographic characteristics including gender, age and education. ${ }^{6,15}$ Those who smoked a fewer number of cigarettes over their lifetime have been associated with increased abstinence rate. ${ }^{6}$ The 
current study only included male smokers and did not show any influence of age on quitting intention or attempt but the light smokers significantly more likely to attempt quit or show intention to quit smoking. Education also showed significant association but no specific trend was noted.

Smoke-free home rules and workplace smoke-free policies seem to encourage smokers to quit or reduce their cigarette consumption. ${ }^{6,15}$ The current study also showed consistent findings, but unfortunately except the mosque none of the place showed strict restrictions. Most of the public places either allowed smoking everywhere or there was no rule. Smoke free air policies often do not cover restaurants. ${ }^{15}$ Despite compelling evidence of efficacy, fewer than $10 \%$ of countries mandate smoke-free bars and restaurants, and more than 60 countries have no smoke-free policies whatsoever. ${ }^{6}$ Enrolling in intensive smoking cessation programs consisting of repeated counselling sessions and pharmacotherapy, which increases the odds for smoking cessation 4.4 fold but no such cessation programme are available in rural Bangladesh. In general, both pharmacotherapies and non- pharmacotherapies are needed to significantly impact smoking cessation rates. ${ }^{6}$ It has also been reported that the social factors associated with intention to undergo smoking cessation treatment are social encouragement to abstain. ${ }^{14}$ The current study also noticed similar findings. Higher intention and quitting attempts were observed when family and colleague supports were more. But unfortunately limited family and colleagues' support was noted. Moreover, support of wife was also not very encouraging. A positive attitude towards smoking cessation in particular, smoking-related beliefs such as selfexempting beliefs and self-efficacy are associated with intention to quit. ${ }^{14}$ Majority of the smokers in the current study did not believe that they could quit smoking.

Use of the 5 Rs may enhance motivation to quit tobacco. These involve having the smoker consider the (1) relevance of quitting (2) risks of tobacco use (3) rewards of quitting (4) roadblocks to quitting (5) having the physician incorporate repetition of this motivational intervention into each clinic visit. ${ }^{16}$ The current study identified lacks in these motivational aspects which could be imparted by family and close people of the smokers.

\section{Conclusion}

Quitting intention and attempt both are at very low level in rural Bangladeshi people, success rate are further very low. Family and social support in quitting, social environment and restrictions in smoking, which are factors to increase quitting attempts, also do not depict encouraging picture. To encourage smoking cessation counselling service for smokers as well as for their friends and family needs to be established.

Acknowledgement: The authors gratefully acknowledge the financial support of Directorate General of Health Services, Bangladesh. Also thankful to the study participants for their kind contributions and other people at study places who helped in organizing field.

\section{References}

1. World Health Organization. Tobacco Products of Today. Egypt: Regional Office for Eastern Mediterranean Region, WHO: 2006. Available from www.emro.who.int/tfi/tfi.

2. World Bank. Curbing the Epidemic: Governments and the Economics of Tobacco Control. Washington DC: World Bank; 1999.

3. Batra A. Treatment of tobacco dependence. Dtsch Arztebl Int. 2011; 108:555-64.

4. CDC. How tobacco smoke causes disease: the biology and behavioral basis for smoking-attributable disease: a report of the Surgeon General. Atlanta, GA: US Department of Health and Human Services, CDC; 2010.

5. Doll R, Peto R, Boreham J, Sutherland I. Mortality in relation to smoking: 50 years' observations on male British doctors. BMJ. 2004; 328:1519-28.

6. $\mathrm{Wu} \mathrm{J} \mathrm{\&} \mathrm{Sin} \mathrm{DD.} \mathrm{Improved} \mathrm{patient} \mathrm{outcome:} \mathrm{when} \mathrm{is}$ it too late? International Journal of COPD. 2011; 6: 259-67.

7. Willemsen MC, Hoogenveen RT \& Lucht FVD. New Smokers and Quitters. Transition in Smoking Status in a National Population. Eur J Public Health. 2002; 12: 136-38.

8. Larabie LC. To What Extent Do Smokers Plan Quit Attempts? Tob Control. 2005; 14: 425-28.

9. Esson KM \& Leeder SR. Millennium Development Goals and Tobacco Control. An Opportunity for Global Partnership. France: World Health Organization; 2004. 
10. Flora MS, Mascie-Taylor CGN, Rahman M. Gender and Locality Differences in Tobacco Prevalence among adult Bangladeshis. Tob Control. 2009; 18: 445-50.

11. White M, Bush J, Kai J, Bhopal R, Rankin J. Quitting smoking and experience of smoking cessation interventions among UK Bangladeshi and Pakistani adults: the views of community members and health professionals. J Epidemiol Community Health. 2006; 60:405-11.

12. Abdullah AS, Driezen P, Quah ACK, Nargis N and Fong GT. Predictors of smoking cessation behavior among Bangladeshi adults: Findings from ITC Bangladesh survey. Tobacco Induced Diseases. 2015; 13:23-32.

14. Rastogi T, Jha P, Reddy KS, Prabhakaran D, Spiegelman D, Stampfer MJ and et al.. Bidi and Cigarette Smoking and Risk of Acute Myocardial Infarction among Males in Urban India. Tob Control. 2005; 14: 356-58.

15. Myung SK, Seo HG, Cheong YS, Park S, Lee WB \& Fong GT. Association of Socio-demographic Factors, Smoking-Related Beliefs, and Smoking Restrictions With Intention to Quit Smoking in Korean Adults: Findings From the ITC Korea Survey. J Epidemiol. 2012; 22: 21-07

16. Kahende JW, Malarcher AM, Teplinskaya A \& Asman KJ. Quit Attempt Correlates among Smokers by Race/Ethnicity. Int J Environ Res Public Health. 2011; 8: 3871-88.

17. Mercer SL, Green LW, Rosenthal AC, Husten CG, Khan LK \& Dietz WH. Possible Lessons from the Tobacco Experience for Obesity Control. Am J Clin Nutr. 2003; 77 Suppl.: 1073S-82S. 